\title{
Early Recruitment of IL-10-Producing B Cells Into Alveoli Improved the Resolution of Acute Lung Injury
}

\author{
Shumin $X^{a}$ Mingzheng Xua Guang-Gang Lib Chunmei Wang ${ }^{a} \quad$ Haihan Song ${ }^{a}$ \\ Jianwen Baia \\ aDepartment of Internal Medicine, Emergency Center, Shanghai East Hospital, Tongji University School \\ of Medicine, Shanghai, 'Intensive Care Unit, Affiliated Bayi Brain Hospital, General Hospital of Beijing \\ Military Command, Beijing, China
}

\section{Key Words}

Acute lung injury $\bullet \mathrm{IL}-10 \cdot \mathrm{B}$ cell

\begin{abstract}
Background: Acute lung injury (ALI) is characterized by rapid induction of inflammation at the alveolar-capillary membrane, and immunosuppressive mechanisms were shown to contribute to its resolution. Despite the central role of lymphocytes in initiating and mediating an inflammatory response, their influx dynamics in ALI has not been examined. Methods: We collected mini-BAL samples from the lung of ALI patients over a maximum period of 7 days, and examined the lymphocyte composition. Results: $\mathrm{CD}^{+}{ }^{+} \mathrm{CD} 4{ }^{+} \mathrm{IFN}$-gamma ${ }^{+}$Th1 cells were detected early on in all patients examined, while IL-10-producing B cells and CD3 ${ }^{+} \mathrm{CD} 4{ }^{+} \mathrm{CD} 25^{\text {hiFoxp3 }}{ }^{+}$ Treg cells appeared later. Interestingly, IL-10-producing B cells appeared earlier than Tregs in most subjects, which possibly exerted anti-inflammatory function before Tregs. We then found that in patients with earlier recruitment of IL-10-producing B cells, the magnitude of Th1 inflammation decreased significantly over time, which was not observed in patients with later recruitment of IL-10-producing B cells. Furthermore, early IL-10-producing B cell recruiters also had significantly earlier recruitment of Tregs and better survival than late IL-10producing B cell recruiters. Conclusion: This study provided data on the alveolar infiltration of lymphocytes during ALI, which suggested an inhibitory role of IL-10-producing B cells in ALI and emphasized the importance of controlling inflammation during the initial stage of ALI.
\end{abstract}




\section{Cellular Physiology Cell Physiol Biochem 2016;38:1752-1760 and Biochemistry Published online: May 09, $2016 \quad \begin{aligned} & \text { DOI: 10.1159/000443114 } 2016 \text { The Author(s). Published by S. Karger AG, Basel } \\ & \text { www.karger.com/cpb }\end{aligned}$ \\ Xu et al.: Breg and Acute Lung Injury}

\section{Introduction}

Acute lung injury (ALI) is a major cause of alveolar-capillary injury with high morbidity and mortality in critically ill patients $[1,2]$. Despite extensive investigations aimed at ALI treatment, current management is mainly supportive, as the underlying mechanisms of ALI pathogenesis have not been fully identified and understood.

The early phase of ALI is characterized by acute inflammation of the alveolar-capillary membrane, resulting in an accumulation of neutrophils, macrophages and proinflammatory cytokines, which are thought to exacerbate inflammation and lung damage [3]. Resolution of inflammation is thought to be driven by immunosuppressive mechanisms, including elevated expression of antiinflammatory cytokines [4], clearance of neutrophils [5], and increase of regulatory T (Treg) cell-mediated immunosuppression [6-8]. Previous studies have shown that Treg transfer into intratracheal LPS-challenged Rag-1-/- mice resulted in earlier resolution of inflammation and reduced levels of alveolar proinflammatory cytokines [6]; adoptive transfer of Treg cells also resolved CXCL12-CXCR4-induced fibroproliferation, a condition associated with worse outcomes $[9,10]$. These studies highlight the participation of immunoregulatory mechanisms in lung injury resolution.

Studies on the regulatory functions of B cells in ALI have been scarce. But in other diseases, B cells have been shown to inhibit Th1/Th17 inflammation during acute inflammation [11], suppress induction of autoimmune disorders [12-14], contribute to the resolution of chronic colitis [15], and suppress antigen-specific $\mathrm{T}$ cell inflammations in infection $[16,17]$. Multiple B cell subsets in mice and humans have been ascribed with regulatory functions, including B-1 cells, marginal zone B cells, and plasmablasts $[18,19]$. In all of these populations, IL-10 production has been considered the primary mediator of immune suppression [20]. Previously, we found that the frequencies of CD19+CD24+CD38 ${ }^{\text {hi }}$ regulatory B cells (Breg) were elevated in senior pneumonia patients and were correlated with reduced risk for ALI development, suggesting a potential role of Breg in inhibiting ALI development. The precise mechanism of Breg action in the initiation and resolution of ALI is still unclear.

In this study, we examined the alveoli of ALI patients over the course of ALI onset, development, and resolution. Our data suggest that early recruitment of IL-10-producing Breg into the alveoli was correlated with early Treg recruitment and contributed to improved ALI outcome.

\section{Materials and Methods}

\section{Study population}

Twenty-eight ALI patients, diagnosed according to the American College of Chest Physicians/Society of Critical Care Medicine Consensus Conference, and the American-European Consensus Conference statements, were recruited. All patients had been previously diagnosed with bacterial pneumonia prior to ALI [21]. Exclusion criteria included diffuse alveolar hemorrhage, severe chronic respiratory disease, directive to withhold intubation, severe chronic liver disease (defined as a Child-Pugh score of $>10$ ), malignancy, using of chronic high-dose immunosuppressive therapy (steroids with equivalent prednisone $>0.5 \mathrm{mg} / \mathrm{kg}$ per day or cytotoxic agents for immunologic disorders), immunosuppression, ALI induction of other causes such as viral infection and sepsis, and chronic heavy smokers and alcohol abusers. Demographic and clinical information of the study population is shown in Table 1. Written informed consent was obtained from each study subject. All procedures followed the guidelines of the Declaration of Helsinki and were approved by the Ethics Boards of East Hospital and Affiliated Bayi Brain Hospital.

\section{BAL extraction}

We performed mini-BAL, a nonbronchoscopic bedside method of performing a small-volume BA, according to a previously published protocol $[6,22]$. Briefly, the Combicath (Plastimed) catheter was introduced into the endotracheal tube through a standard bronchoscopy adapter, and then gently pushed 


\section{Cellular Physiology Cell Physiol Biochem 2016;38:1752-1760 and Biochemistry Published online: May 09, $2016 \quad \begin{aligned} & \text { DOI: 10.1159/000443114 } \\ & \begin{array}{l}\text { (c) } 2016 \text { The Author(s). Published by S. Karger AG, Basel } \\ \text { www.karger.com/cpb }\end{array}\end{aligned}$ \\ Xu et al.: Breg and Acute Lung Injury}

into the lung until it became wedged in a distal airway. Two to 4 20-mL aliquots of buffered saline and a 5-mL air bolus were injected into the lung. The BAL liquid was then retrieved and catheter removed. Cells obtained from BAL were washed and suspended in RPMI 1640 supplemented with 10\% FBS, Pen Strep and L-glutamine (Invitrogen), and were prepared for flow cytometry within 2 hours.

Flow cytometry

Cells were first incubated with Human TruStain FcX Fc Receptor Blocking Solution (BioLegend) for $10 \mathrm{~min}$, and then with anti-human CD3, CD4, CD19 and CD25 monoclonal antibodies in staining buffer (PBS supplemented with $2 \%$ FBS and $0.1 \%$ sodium azide) for $30 \mathrm{~min}$ at $4{ }^{\circ} \mathrm{C}$. In a subset of experiments, anti-human CD10, CD20, CD21, CD24, CD27 and CD38 were also included to analyze
Table 1. Demographic and baseline clinical characteristics of the study population. All continuous values were expressed as mean \pm SD

\begin{tabular}{ll}
\hline & Patients \\
\hline $\mathrm{N}$ & 28 \\
Age, $\mathrm{y}$ & $63.2 \pm 13.4$ \\
$\mathrm{Sex}, \mathrm{F} / \mathrm{M}$ & $13 / 15$ \\
$\mathrm{BMI}$ & $22.8 \pm 5.4$ \\
Ever smoker, N (\%) & $8(28.5)$ \\
APACHE II Score & $21.3 \pm 6.0$ \\
Pneumonia severity index & $116 \pm 10.9$ \\
Respiratory rate $_{\mathrm{SaO}_{2} / \mathrm{FiO}_{2}}$ & $23.4 \pm 1.8$ \\
$\mathrm{Bilateral} \mathrm{infiltrates,} \mathrm{N} \mathrm{( \% )}$ & $205 \pm 55.4$ \\
Pleural effusion, N (\%) & $7(64.3)$ \\
Mortality, N (\%) & $7(25)$ \\
\hline
\end{tabular}

the surface marker expression of IL-10-producing B cells. Cells were then washed in staining buffer twice and permeabilized in Cytofix/Cytoperm Fixation/Permeabilization Solution (BD) for 15 min at $4{ }^{\circ} \mathrm{C}$. Antihuman IFN-gamma (BioLegend), IL-10 and Foxp3 monoclonal antibodies (BD) were then added to the cells in diluted PermWash buffer (BD) for $30 \mathrm{~min}$ at $4^{\circ} \mathrm{C}$, after which the cells were washed and stained samples were run in a FACSFortessa cytometer (BD).

Statistics

All statistical analyses were performed using Prism 6 Software (GraphPad). Mean \pm standard deviation was shown when applicable. P values less than 0.05 was accepted as statistically significant.

\section{Results}

IL-10-producing B cells are present in ALI patients

We first examined immune cell composition in ALI patients. Patients were enrolled within 4 days after ALI onset. Mini-BAL and blood samples were collected after enrolment at various time points between Day 0 (time of ALI onset) and Day 6. The immune cell composition in mini-BAL was analyzed by flow cytometry. We were able to find both $\mathrm{CD}^{+}{ }^{+} \mathrm{CD} 19^{-} \mathrm{T}$ cells and CD3-CD19+ $\mathrm{B}$ cells in mini-BAL (Fig. 1A).

$\mathrm{T}$ cells and $\mathrm{B}$ cells are composed of various subsets with different functions. By using IFN-gamma as a Th1 functional marker, CD25 and Foxp3 as Treg markers, and IL-10 as a regulatory B cell functional marker, we observed that Th1, Treg, and IL-10-producing B cell subsets were present in mini-BAL (Fig. 1B). The roles of Th1 and Treg infiltration in ALI have been studied previously. Here, we focused on IL-10-producing B cells [6, 23]. By surface marker expression, the majority of these B cells presented a CD10, CD $20^{10 /+}$, CD27 ${ }^{+}$ expression pattern, which is consistent with activated memory or differentiating plasmablast phenotypes (Fig. 1C) [24, 25]. We did not find that these B cells were particularly high in terms of CD24 or CD38 expression, common markers of regulatory B cells in autoimmune diseases [26].

Varying dynamics of IL-10-producing B cells were observed.

We then examined the dynamics of T cell and B cell subsets within the mini-BAL during ALI. Since not all patients were immediately enrolled after ALI onset, patient timelines were normalized according to the date of the onset instead of the date of the enrolment. We found that at Day 0, a strong influx of Th1 cells was present in all patients with Day 0 data available (Fig. 2A). In 10 out of 27 patients, the high frequency of Th1 cells persisted 


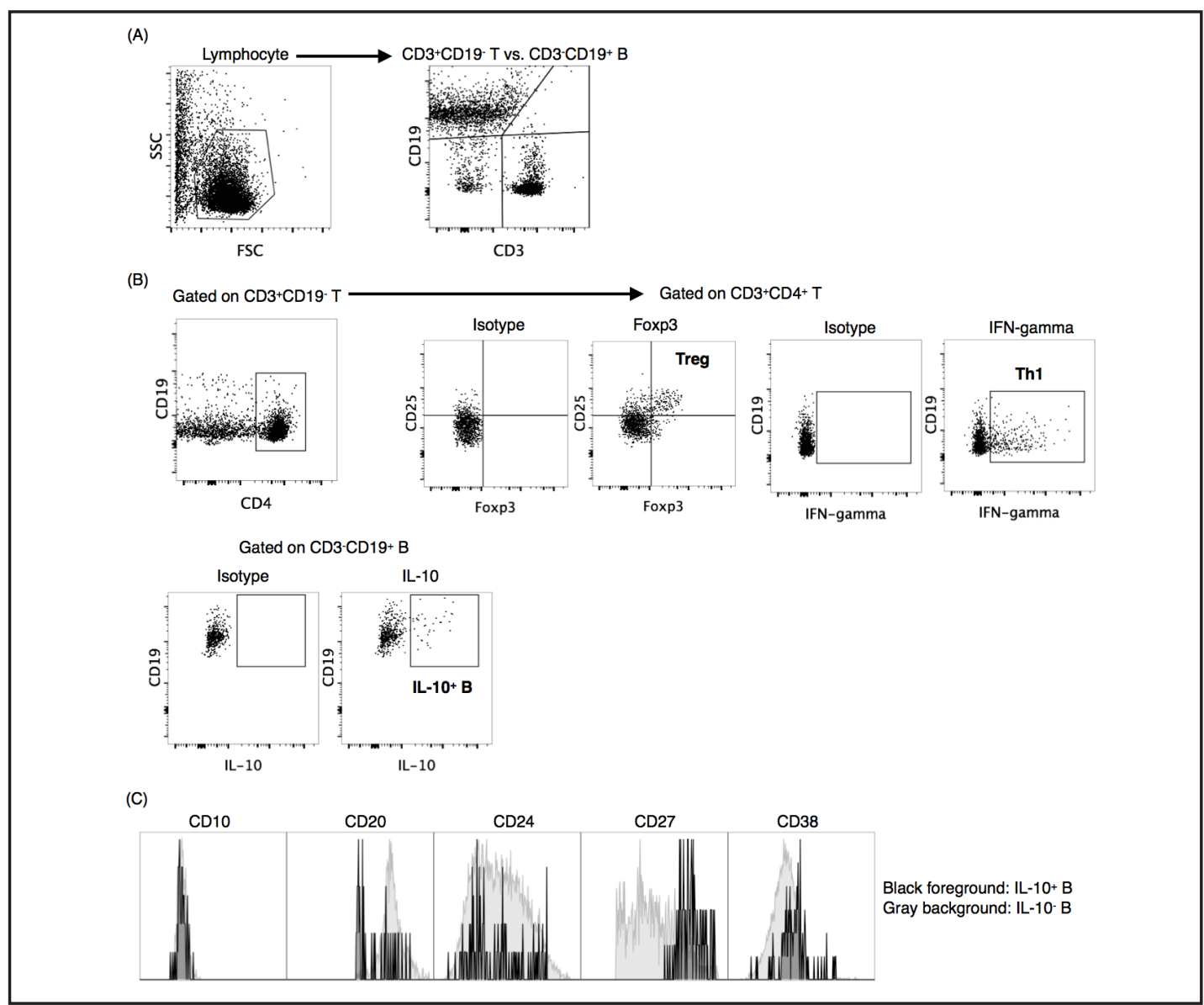

Fig. 1. Discovery of T cells, B cells, Th1 cells, Treg cells, and IL-10-producing B cells in BAL fluid. All graphs are from representative mini-BAL samples from ALI patients. (A) Gating strategy of CD3 ${ }^{+}$CD19- $\mathrm{T}$ cells and CD3 ${ }^{-C D} 19^{+}$B cells. (B) Gating strategy of $\mathrm{CD}^{+}{ }^{+} \mathrm{CD} 4^{+} \mathrm{CD} 25^{\text {hi }}$ Foxp3 ${ }^{+}$Tregs, $\mathrm{CD}^{+} \mathrm{CD} 4{ }^{+}$IFN-gamma ${ }^{+}$Th1 cells and CD3-CD19+IL-10+ B cells. (C) Surface marker expression of IL-10+ B cells (black foreground) vs. IL-10- B cells (gray background).

or further increased over the course of ALI, while in 17 out of 27 patients, the frequency of Th1 cells showed a decreasing trend, and had a lower Th1 frequency in the last mini-BAL sample (Day 4, 5 or 6, depending on the patient) compared to the first mini-BAL sample (Day $0,1,2$, or 3, depending on the patient). The starting date of Treg influx, however, was highly variable, from as early as Day 0 to as late as Day 5. Six out of 28 patients had Treg making the first appearance in mini-BAL at Day 0, 6 at Day 1, 5 at Day 2, 4 at Day 3, and the remaining 7 between Day 4 and Day 5. Such dynamic was also observed in IL-10-producing B cells. Eleven out of 28 patients had IL-10-producing B cells at Day 0 mini-BAL, 4 patients at Day 1, 5 patients at Day 2, 5 patients at Day 3, and 2 patients at Day 5. One patient had no IL-10producing B cell infiltration throughout the course of ALI. The initial and final frequencies of Th1, Treg and IL-10-producing B cells are summarized in Figure 2B. Interestingly, IL-10producing B cells on average appeared earlier in mini-BAL than Tregs, with a median of Day 1 and mean of Day 1.44 for IL-10-producing B cells and a median of Day 2 and mean of Day 2.11 for Tregs (Fig. 2C).

The influx of IL-10-producing B cells were inversely correlated with Th1 inflammation

IL-10-producing B cells were shown to suppress Th1 and cytotoxic T cell inflammation $[16,17]$. Using the median of Day 1 after ALI onset as a divider, we grouped our patients into early IL-10-producing B cell recruiters, if IL-10-producing B cells first appeared at Day 0 and 


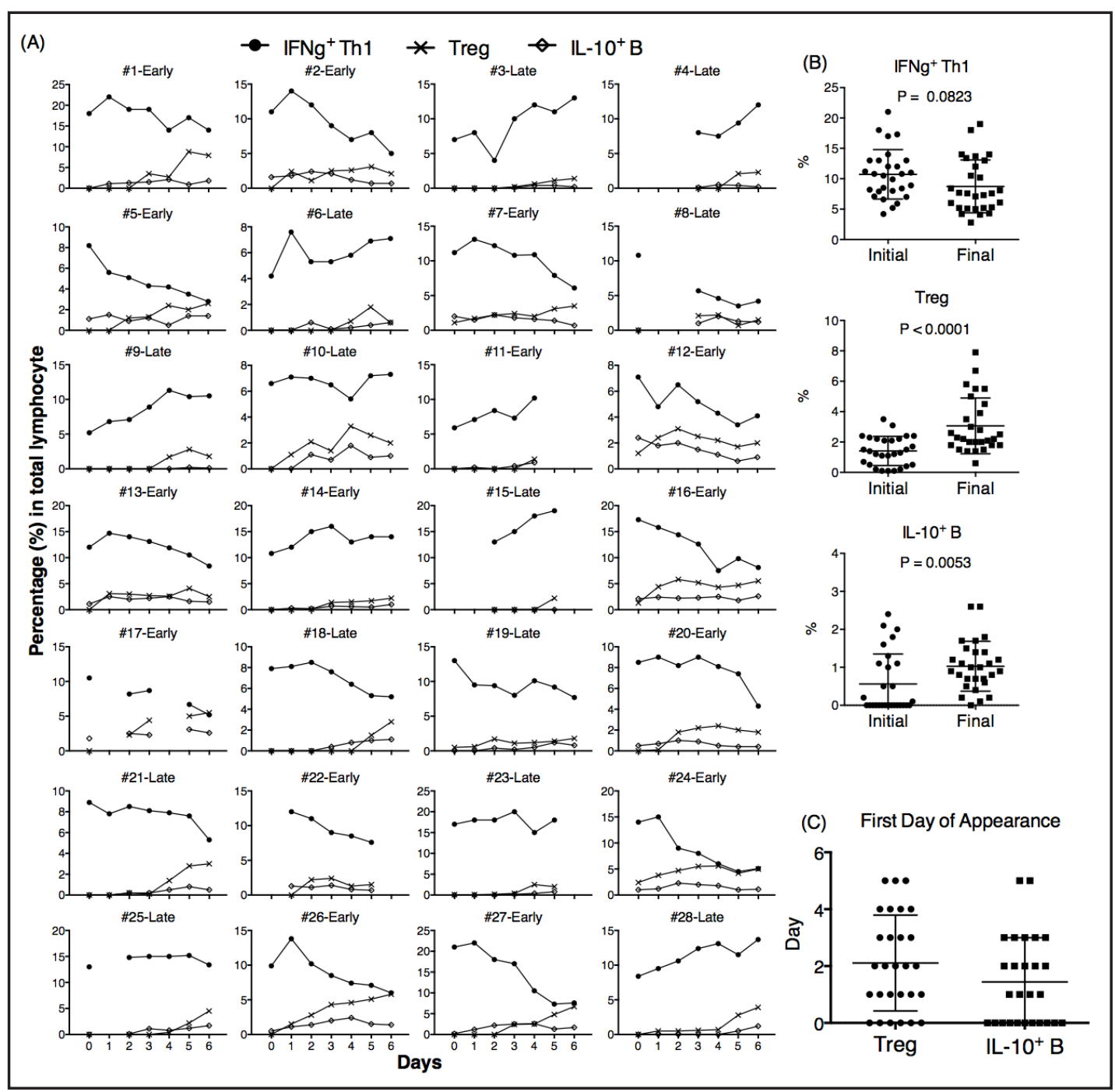

Fig. 2. Th1, Treg and IL-10-producing B cell infiltration dynamics in ALI patients. (A) The frequencies of $\mathrm{CD}^{+}{ }^{+} \mathrm{CD} 4^{+}$IFN-gamma ${ }^{+}$Th1 cells (filled circle), $\mathrm{CD}^{+} \mathrm{CD} 4^{+} \mathrm{CD} 25^{\text {hi }}$ Foxp $3^{+}$Tregs (cross), and CD3-CD $19^{+}$IL- $10^{+} \mathrm{B}$ cells (open diamond) in each patient's mini-BAL samples, as determined by previously established gatings. The percentages of the cell types in lymphocytes were shown on the $\mathrm{x}$-axis, and the numbers of days after ALI onset were shown on the y-axis. Early IL-10-producing B cell recruiters were defined as the subjects who had IL-10-producing B cells at Day 0 or Day 1 after ALI onset; otherwise, the subjects were classified as late IL-10-producing B cell recruiters. (B) Summary of the percentages of CD3 ${ }^{+} \mathrm{CD} 4^{+} \mathrm{IFN}$-gamma ${ }^{+} \mathrm{Th} 1$ cells, $\mathrm{CD}^{+}{ }^{+} \mathrm{CD} 4^{+} \mathrm{CD} 25^{\text {hi }}{ }^{\mathrm{Foxp}} 3^{+}$Tregs, and CD3-CD19+IL-10+ $\mathrm{B}$ cells in the initial and final samples of the patients' mini-BAL. The initial sample refers to the Day 0 samples in all subjects except \#4 (Day 4), \#15 (Day 2), and \#22 (Day 1), while the final sample refers to the Day 6 samples in all subjects except \#11 (Day 4), \#15 (Day 5), \#22 (Day 5) and \#23 (Day 5). (C) The first day of appearance of Tregs and IL-10-producing B cells in each patient, after ALI onset.

Day 1, and late IL-10-producing B cell recruiters, if IL-10-producing B cells first appeared at or after Day 2 (Fig. 2A). These two groups of patients did not have a significant difference in terms of the initial (first mini-BAL) and final (last mini-BAL) magnitude of Th1 inflammation (Fig. 3A). However, the early recruiters showed significant downregulation of Th1 frequency over the study period, as evident by the lower Th1 percentage in the last mini-BAL compared to the first, while no such downregulation was found in late recruiters (Fig. 3B). 
Fig. 3. Th1 influx dynamics in early vs. late recruiters of IL-10-producing B cells. (A) The initial (first sample day after ALI onset) and final (last sample day after ALI onset) frequencies of Th1, as a percentage of total lymphocytes, in early and late recruiters. Unpaired $t$ test with Welch's correction. (B) The changes between the initial and final Th1 frequency in early and late recruiters. Paired $t$ test.

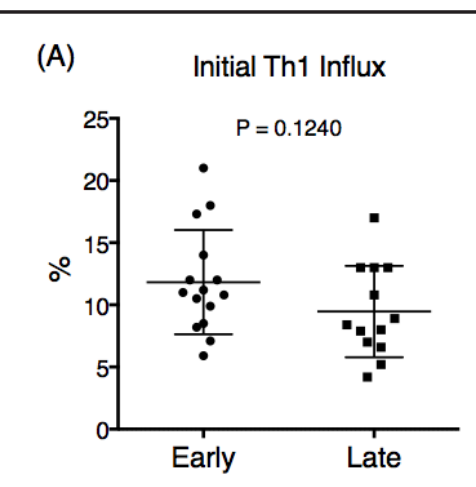

(B)

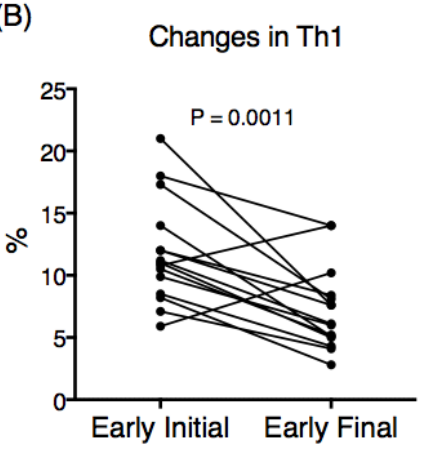

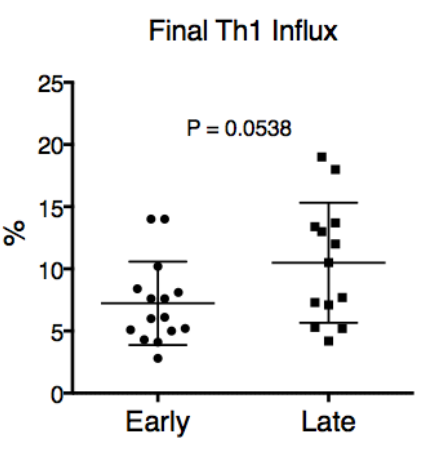

Changes in Th1

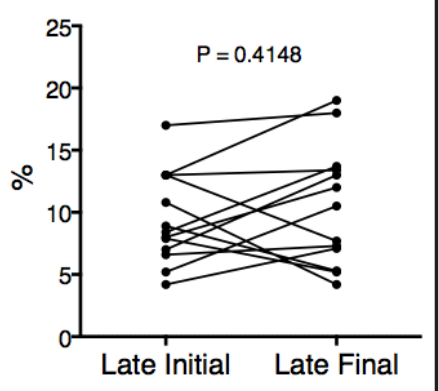

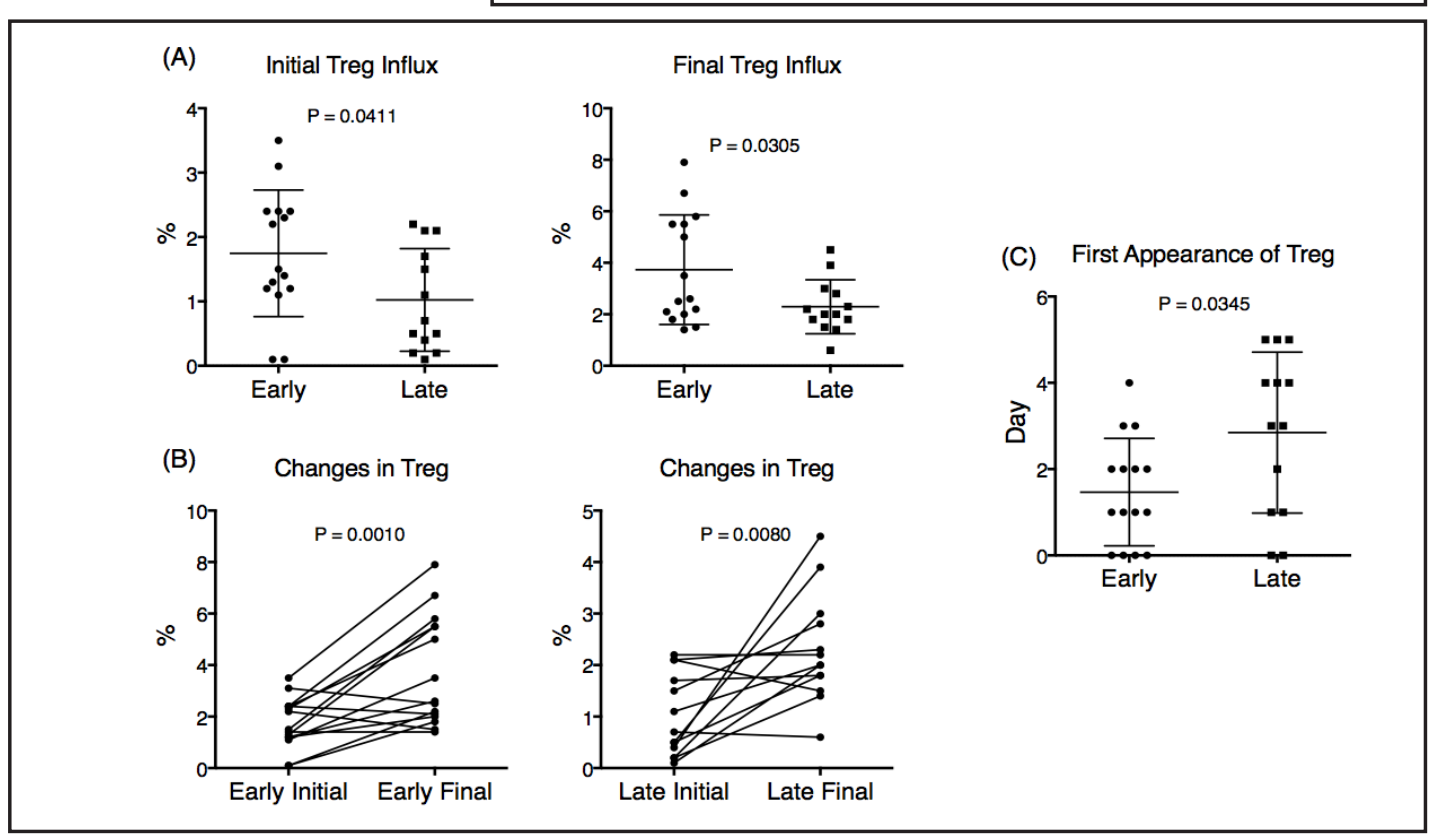

Fig. 4. Treg influx dynamics in early vs. late recruiters of IL-10-producing B cells. (A) The initial (first day of Treg appearance after ALI onset) and final (last sample day of Treg presence) frequencies of Treg, as a percentage of total lymphocytes, in early and late recruiters. Unpaired $t$ test with Wlech's correction. (B) The changes between the initial and final Th1 frequency in early and late recruiters. Paired $t$ test. (C) The first day of appearance of Tregs, in early and late IL-10-producing B cell recruiters. Unpaired $t$ test with Wlech's correction.

The strength of Treg influx was also correlated with the influx of IL-10-producing B cells, since early IL-10-producing B cell recruiters had significantly higher frequencies of Tregs, both at initial and final time points (Fig. 4A). Both early and late IL-10-produing B cell recruiters had increased Treg frequency over the study period (Fig. 4B). Early IL-10- 
Fig. 5. The association of Th1 and IL-10-producing B cell dynamics with disease outcome. (A) The initial and final magnitude of Th1 influx in patients who survived (alive) and in patients who died (dead) following ALI. Unpaired $t$ test with Wlech's correction. (B) The numbers of early and late IL-10-producing B cell recruiters that were alive or dead following ALI. Chi-square test.

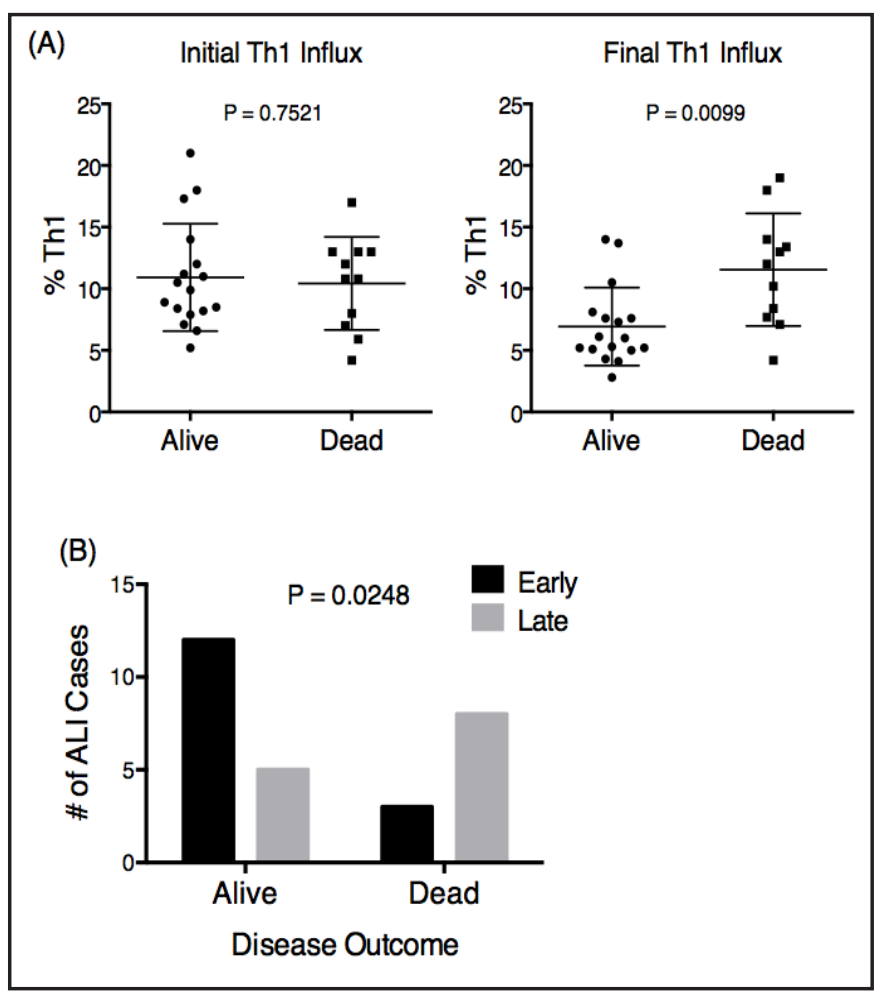

producing B cell recruiters had significantly earlier Treg appearance in the mini-BAL than late recruiters (Fig. 4C). Together, these data suggest that IL-10-producing B cells might influence the strength of Treg infiltration in the mini-BAL by increasing the Treg frequency and by facilitating Treg recruitment.

ALI patients with early IL-10-producing B cell infiltration showed improved prognosis

The effect of Treg cells in injury repair following ALI has been studied elsewhere [6, 7]. To evaluate the role of Th1 and IL-10-producing B cell influx in injury recovery after ALI onset, we followed the study patients for the disease outcome. While the initial Th1 influx did not affect the mortality after ALI, patients who survived the disease showed significantly lower final Th1 influx (Fig. 5A), suggesting that the suppression of Th1 inflammation was crucial to the resolution of the disease. In addition, the early IL-10-producing B cell recruiters had significantly lower mortality than late recruiters (Fig. 5B), implicating a role of IL-10producing B cell influx in ALI resolution.

\section{Discussion}

Despite extensive studies on the exacerbating role of inflammation in ALI induction $[3,27,28]$, to the extent of our knowledge, the lymphocyte trafficking dynamics in ALI patients has not been examined in detail. Therefore, we collected ALI mini-BAL samples and analyzed the lymphocyte composition over a 7-day timeline. We first identified the presence of $\mathrm{CD}^{+} \mathrm{CD}^{+}$IFN-gamma ${ }^{+} \mathrm{Th} 1$ cells in all 28 patients at the initial sample date, suggesting a participation of Th1 cells in ALI inflammation. In contrast, $\mathrm{CD} 3^{+} \mathrm{CD} 4^{+} \mathrm{CD} 25^{\text {hi }}$ Foxp $3^{+}$Treg cells were present in only a subset of the ALI patients at the initial sample date, and gradually appear over the 7-day period. Similarly, IL-10-producing B cells also had varying influx dynamics in different patients, but interestingly, IL-10-producing B cells appeared earlier than Tregs in most subjects. We then examined the association between the dynamics of these cell types, and found that in patients with earlier recruitment of IL-10-producing B cells, the magnitude of Th1 inflammation decreased significantly over time, while patients 


\section{Cellular Physiology Cell Physiol Biochem 2016;38:1752-1760 \begin{tabular}{l|l} 
DOI: 10.1159/000443114 & $\begin{array}{l}\text { O 2016 The Author(s). Published by S. Karger AG, Basel } \\
\text { www.karger.com/cpb }\end{array}$
\end{tabular} \\ Xu et al.: Breg and Acute Lung Injury}

with later recruitment of IL-10-producing B cells did not show this trend. The early IL-10producing B cell recruiters also had significantly earlier recruitment of Tregs. Together, these data examined the lymphocyte infiltration in ALI and suggested an association between different lymphocyte subsets. Furthermore, the connection between earlier regulatory cell infiltration, decreasing Th1 inflammation, and better survival emphasized the importance of controlling inflammation during the initial stages of ALI.

The earlier presence of IL-10-producing B cells compared to Tregs suggests that these B cells may help establish a suppressive and anti-inflammatory environment before the arrival of Treg cells. In previous studies using autoimmune mouse models, the depletion of B cells prior to, but not after, the induction of experimental autoimmune encephalomyelitis increased the disease severity, suggesting that regulatory B cells functions by establishing a more anti-inflammatory environment [12]. In our cohort, the early recruiters had significantly better survival than the late recruiters and had significantly more reduction of Th1 inflammation over the sample collection period, suggesting a role of early IL-10producing B cell recruitment in ALI resolution.

Whether IL-10-producing B cells could directly suppress Th1 inflammation through promoting Treg differentiation, and/or infiltration into the alveoli requires further study. IL10 production by B cells and antibody-secreting plasmablasts was shown to inhibit dendritic cells in generating pathogenic T cells [19], suppressed Th1 differentiation, promoted $\operatorname{Tr} 1$ cell and Treg cell differentiation, and suppressed IFN-gamma production from $\mathrm{CD}^{+} \mathrm{T}$ cells $[16,17]$. Previous studies in parasitic helminth infection models also demonstrated a role of IL-10 from B cells in inducing pulmonary infiltration of $\mathrm{CD} 4^{+} \mathrm{CD} 25^{+} \mathrm{Foxp} 3^{+}$Tregs, which controlled airway inflammations. These studies demonstrated that IL-10-produing B cells could act through multiple mechanisms in suppressing inflammation during ALI. The potential therapeutic uses of these mechanisms require further investigation.

We identified $B$ cells with potential regulatory activities by using IL-10 production as a functional marker, instead of using other regulatory B cell markers, such as CD2 $4{ }^{\text {hi }}$ CD $38^{\text {hi }}$ and $\mathrm{CD}_{1} \mathrm{~d}^{\text {hi }} \mathrm{CD}^{+}$, in autoimmune diseases and infections. Since some of these previous markers were shared with immature/transitional B cells and innate-like B-1 cells, we attempted to avoid mixing these cell types with our B cells of interest. The choice of IL-10, however, came with the caveat that IL-10 is also a B cell development and plasmablast differentiation cytokine. Indeed, our surface marker examination suggests that this IL-10-producing B cell population in the mini-BAL samples most closely resembled activated memory B cells or differentiating plasmablasts. Whether these B cells have proinflammatory roles, and whether they participate in host defense prior to ALI induction needs further studies.

\section{Acknowledgment}

This work was supported by the Western Medicine Leader Program of Shanghai Municipal Science and Technology Commission (15411962300).

\section{Disclosure Statement}

None.

\section{References}

1 Maybauer MO, Maybauer DM, Herndon DN: Incidence and outcomes of acute lung injury. N Eng J Med 2006;354:416-417; author reply 416-417.

2 Bice T, Li G, Malinchoc M, Lee AS, Gajic O: Incidence and risk factors of recurrent acute lung injury. Crit Care Med 2011;39:1069-1073. 


\section{Cellular Physiology Cell Physiol Biochem 2016;38:1752-1760 \begin{tabular}{l|l} 
DOI: 10.1159/000443114 & $\begin{array}{l}\text { O 2016 The Author(s). Published by S. Karger AG, Basel } \\
\text { www.karger.com/cpb }\end{array}$
\end{tabular} \\ Xu et al.: Breg and Acute Lung Injury}

3 Ware L, Matthay M: The acute respiratory distress syndrome. N Engl J Med. 2000;342:1334-1349.

4 Henson PM: Dampening inflammation. Nat Immunol 2005;6:1179-1181.

5 Henson PM, Hume DA: Apoptotic cell removal in development and tissue homeostasis. Trends Immunol 2006;27:244-250.

6 D’Alessio FR, Tsushima K, Aggarwal NR, West EE, Willett MH, Britos MF, Pipeling MR, Brower RG, Tuder RM, McDyer JF, King LS: CD4+CD25+Foxp3+ Tregs resolve experimental lung injury in mice and are present in humans with acute lung injury. J Clin Invest 2009;119:2898-2913.

7 Song H, Zhou Y, Li G, Bai J: Regulatory T cells contribute to the recovery of acute lung injury by upregulating Tim-3. Inflammation 2015;38:1267-1272.

8 Nakajima T, Suarez CJ, Lin K-W, Jen KY, Schnitzer JE, Makani SS, Parker N, Perkins DL, Finn PW: T cell pathways involving CTLA4 contribute to a model of acute lung injury. J Immunol 2010;184:5835-5841.

9 Tao Z, Yuan Y, Liao Q: Alleviation of Lipopolysaccharides-Induced Acute Lung Injury by MiR-454. Cell Physiol Biochem 2016;38:65-74.

10 Marshall RP, Bellingan G, Webb S, Puddicombe A, Goldsack N, McAnulty RJ, Laurent GJ: Fibroproliferation occurs early in the acute respiratory distress syndrome and impacts on outcome. Am J Respir Crit Care Med 2000;162: 1783-1788.

11 Carter NA, Vasconcellos R, Rosser EC, Tulone C, Muñoz-Suano A, Kamanaka M, Ehrenstein MR, Flavell RA, Mauri C: Mice lacking endogenous IL-10-producing regulatory B cells develop exacerbated disease and present with an increased frequency of Th1/Th17 but a decrease in regulatory T cells. J Immunol 2011;186:5569-5579.

12 Matsushita T, Yanaba K, Bouaziz JD, Fujimoto M, Tedder TF: Regulatory B cells inhibit EAE initiation in mice while other B cells promote disease progression. J Clin Invest 2008;118:3420-3430.

13 Blair PA, Noreña LY, Flores-Borja F, Rawlings DJ, Isenberg DA, Ehrenstein MR, Mauri C: CD19(+)CD24(hi) CD38(hi) B cells exhibit regulatory capacity in healthy individuals but are functionally impaired in systemic Lupus Erythematosus patients. Immunity 2010;32:129-140.

14 Mauri C, Gray D, Mushtaq N, Londei M: Prevention of arthritis by interleukin 10-producing B cells. J Exp Med 2003;197:489-501.

15 Mizoguchi A, Mizoguchi E, Smith RN, Preffer FI, Bhan AK: Suppressive role of B cells in chronic colitis of T cell receptor alpha mutant mice. J Exp Med 1997;186:1749-1756.

16 Liu J, Zhan W, Kim CJ, Clayton K, Zhao H, Lee E, Cao JC, Ziegler B, Gregor A, Yue FY, Huibner S, MacParland S, Schwartz J, Song HH, Benko E, Gyenes G, Kovacs C, Kaul R, Ostrowski M: IL-10-producing B cells are induced early in HIV-1 infection and suppress HIV-1-specific T cell responses. PLoS One 2014;9.

17 Das A, Ellis G, Pallant C, Lopes ARR, Khanna P, Peppa D, Chen A, Blair P: IL-10-producing regulatory B cells in the pathogenesis of chronic hepatitis B virus infection. J Immunol. 2012;189:3925-3935.

18 Iwata Y, Matsushita T, Horikawa M, DiLillo DJ, Yanaba K, Venturi GM, Szabolcs PM, Bernstein SH, Magro CM, Williams AD, Hall RP, St Clair EW, Tedder TF: Characterization of a rare IL-10-competent B-cell subset in humans that parallels mouse regulatory B10 cells. Blood 2011;117:530-541.

19 Matsumoto M, Baba A, Yokota T, Nishikawa H, Ohkawa Y, Kayama H, Kallies A, Nutt SL, Sakaguchi S, Takeda K, Kurosaki T, Baba Y: Interleukin-10-Producing Plasmablasts Exert Regulatory Function in Autoimmune Inflammation. Immunity 2014;41:1040-1051.

20 Mauri C: Regulation of immunity and autoimmunity by B cells. Curr Opin Immunol 2010;22:761-767.

21 Organization WH: International Classification of Diseases (ICD). In: World Health Organization [Internet]. 2011. http://www.who.int/classifications/icd/en/

22 Kollef MH, Bock KR, Richards RD, Hearns ML: The safety and diagnostic accuracy of minibronchoalveolar lavage in patients with suspected ventilator-associated pneumonia. Ann Intern Med 1995;122:743-748.

23 Wynn TA: Integrating mechanisms of pulmonary fibrosis. J Exp Med 2011;208:1339-1350.

24 Liu S, Tang J, Huang L, Xu Q Ling X, Liu J: Cordyceps Militaris Alleviates Severity of Murine Acute Lung Injury Through miRNAs-Mediated CXCR2 Inhibition. Cell Physiol Biochem 2015;36:2003-2011.

25 Moir S, Fauci AS: B cells in HIV infection and disease. Nat Rev Immunol 2009;9:235-245.

26 Mauri C, Blair PA: Regulatory B cells in autoimmunity: developments and controversies. Nat Rev Rheumatol 2010;6:636-643.

27 Grommes J, Soehnlein 0: Contribution of neutrophils to acute lung injury. Mol Med 2011;17:293-307.

28 Li L, Zhang H, Min D, Zhang R, Wu J, Qu H, Tang Y: Sox9 activation is essential for the recovery of lung function after acute lung injury. Cell Physiol Biochem 2015;37:1113-1122. 